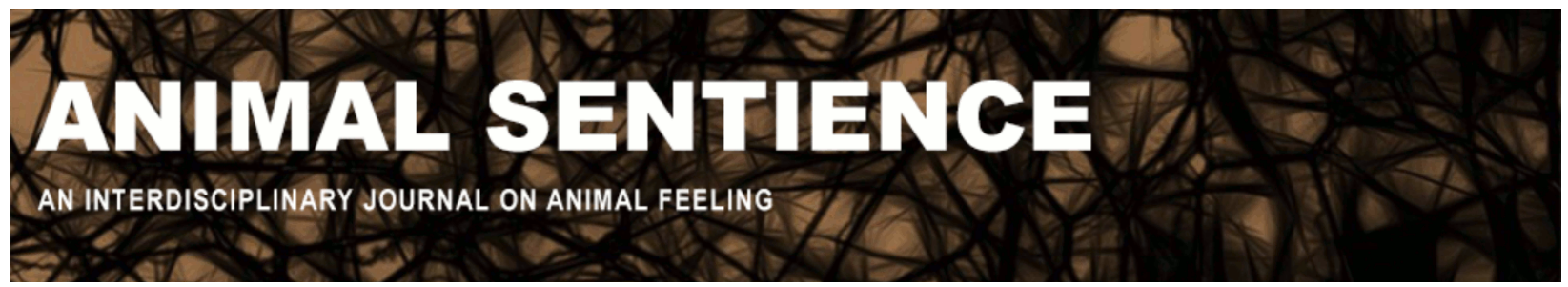

Clarke, Nancy (2016) Sentience and animal welfare: Affirming the science and addressing the skepticism. Animal Sentience 5(3)

DOI: 10.51291/2377-7478.1009

Date of submission: 2015-04-05

Date of acceptance: 2015-12-13

(c)

This article has appeared in the journal Animal

Sentience, a peer-reviewed journal on animal

cognition and feeling. It has been made open access,

free for all, by WellBeing International and deposited

in the WBI Studies Repository. For more information,

please contact

wbisr-info@wellbeingintl.org.

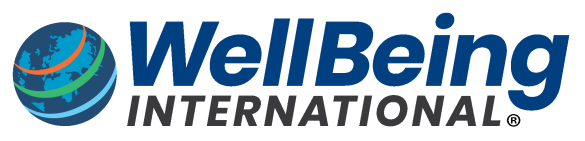

SOLUTIONS FOR PEOPLE, ANIMALS AND ENVIRONMENT 


\title{
Sentience and animal welfare: Affirming the science and addressing the skepticism
}

Commentary on Broom on Animal Welfare

\author{
Nancy Clarke \\ World Animal Protection
}

\begin{abstract}
Broom's (2014) book is a well-researched and thoroughly written exploration and evaluation of the journey from the origins of animal welfare science to what we can say we now know and need to consider in relation to animal sentience and welfare. This book will help to counter any skepticism among academics and policy makers.
\end{abstract}

Nancy Clarke nancyclarke@worldanimalprotection.org is International Veterinary Education Manager at World Animal Protection. Nancy's qualifications and experience are in human psychology, applied animal behaviour and welfare and education. She's been engaged in tertiary animal welfare education and research for over 8 years, both as a Lecturer and Programme Director, working with students of animal technology, animal behaviour and welfare, veterinary nursing and veterinary science. http://www.worldanimalprotection.org/

Animals have been identified as "sentient beings"' by the European Union ever since the enactment of the Treaty of Lisbon in 2007. Eight years afterward, the French Parliament has now adopted a bill according to animals the legal status of "living beings endowed with sentience" in the Civil Code. But what does "sentience" mean? What do science and sentience have to do with animal welfare? Why are we interested in sentience? How do people view species perceived to be like us or unlike us? Which animals should be protected, and from what stage of development?

Who better to help answer questions such as these than Donald Broom, the first ever Professor of Animal Welfare in the world, in his latest book. This book is a testament to the growing recognition and importance of animal sentience welfare in society. The book specifically aims "to counter widely stated human prejudices" like "the idea that humans are very different from all other animals" and "that mammals have brains that function at a completely different level from those of birds, fish or invertebrate animals such as octopus, squid, lobsters or spiders."

The reader is first walked through the history and evolution of science of animal welfare. Then, based on the highly objective evaluation provided throughout this book on the findings of animal welfare science, the author offers a definitive section on which animals are sentient. This, in Broom's opinion, includes all mammals and fish, cephalopods and decapod crustaceans. Alongside chapters concerning the ins and outs of welfare science (for example, the physiological basis of sentience and welfare assessment), Broom also discusses attitudes towards animal sentience as well as ethical decision-making amongst the diversity of the public and consumers, legislators, politicians, veterinarians, scientists, producers, 
suppliers and commercial businesses. It is on these elements of the book concerning attitudes to animal welfare that the present review is primarily focused.

Broom affirms the investigation of animal sentience as a serious scientific endeavour. However, it is just as important for the reader to understand how the science of animal sentience may influence and shape people's attitudes toward animal sentience. To what extent can and do the findings of animal welfare science influence what and how people think about animals and what they do about animal welfare?

Broom discusses the changes in what we feel we know and think about animal sentience in recent years. He points out that the degree to which people think an animal may be sentient will vary according to aesthetic factors such as how physically similar or different they are to humans, how beautiful they are perceived to be, how big they are, aspects of their cognition (such as how quickly they can learn), and their feelings (such as what emotions they experience).

Broom makes it clear, however, that the role animals play in providing people with companionship or food, or as research subjects or pests, has a great influence on the extent to which the sentience of an animal, or in fact a species, is taken into consideration. Broom goes on to assert that, regardless of how people intend to use or treat animals, animal sentience should be acknowledged: "A rabbit is a rabbit and each one feels pain or has cognitive function." What might also be useful here would be an exploration of the complex, yet critical, relationship between our knowledge, attitudes and subsequent behaviours in relation to animal sentience.

In examining the relationship between attitudes to animal welfare and consumer pressure, Broom highlights a shift towards a "pull society" in which consumers actively shape decision making by governments and by food retail companies when it has an impact on animal welfare. The sources of information that drive consumers' views about animal sentience and welfare remain vague, and the valuable role of certain non-governmental organisations in increasing awareness of animal sentience and welfare issues amongst consumers is not discussed. Consumers may be not likely to reach for a book that combines a technical and complex writing style with minimal imagery. Those that might will benefit from having a scientific background.

The greater challenge may lie in the author's aim to confront "the idea that humans are very different from all other animals" within the academic community. Broom makes some controversial statements: "The prejudices of those in the academic community may well be the reason why scientists are not willing to say that non-human animals can be conscious, aware or have feelings." He also respectfully highlights that "The reluctance of scientists to attribute complex abilities and feelings to non-humans has slowed the development of our knowledge of sophisticated brain function in non-humans. Researchers have been unwilling to carry out studies in the area because, if they used words such as awareness, feeling, emotion and mood, they risked the scorn of other scientists and having difficulties in future in obtaining research funding and getting papers published." This book should be considered essential reading for the wider scientific and academic communities to counter the subjectivity with which the valid and robust results of animal welfare research are reputedly interpreted. 
It is important to note a small section concerning the role of education in animal welfare is included at the end of the book, possibly implying the pivotal role of education as a vehicle for raising awareness and increasing understanding of animal sentience and welfare. The author rightly points out that "There has been rapid refinement of concepts of animal welfare science and development of a wide range of sophisticated measurements of welfare. The education of veterinary, animal science, and biology students has not kept pace with these developments, so there is an urgent need for animal welfare courses to be designed and taught in universities." It would be useful if Broom, and the academic community in general, emphasised and explored further the important question of why increased knowledge of animal sentience may not always serve to boost belief in animal sentience especially amongst those in the veterinary profession, who are in a unique position to advocate for better animal welfare.

In conclusion, Broom demonstrates how, through patient work over a series of decades, previously discounted questions about the existence and investigation of animal sentience and welfare have evolved into a thriving and valid area of scientific research. This should inform how we view, use and manage animals and their welfare in the future. It has revolutionised our understanding of animal sentience and has important consequences for how we decide to use animals. The author advises that when analysing and writing about their research, scientists "should not be afraid to use concepts such as emotion, feeling, mood, pain, fear, happiness, aware, consciousness, stress, need and welfare in presenting results. No concept should be avoided because there might be those who would criticise the use of complex concepts on the grounds that there must be parsimony in all description. If the subject is complex, some of concepts must be complex." It is a formidable milestone when such a well-respected biologist writes a book that summarises the key findings from animal welfare science and offers conclusions about the sentience of specific kinds of animals. It is to be hoped that this book will serve as an antidote to some of the longstanding skepticism within the academic community.

The real question is what people, including scientists and policy makers, decide to do with all this new information about animal sentence and welfare now that is exists. Innovative suggestions are made by the author about policy changes that need to be made in the light of the findings on animal sentience and welfare.

How the scientific findings on animal sentience are to be applied to improve animal welfare now becomes the pressing issue, particularly in practical policy-making. Though animals are now defined in the French Civil Code according to their ability to "feel," some have argued that the French law is too vague to make a real impact and that what is meant by the word "sentient" needs to be made explicit. Books such as Broom's will certainly help to narrow the gap between how animal sentience is recognised in policy and in practice.

\section{References}

Broom, D.M. (2014). Sentience and animal welfare. Wallingford: CABI. 